\title{
Delirium in Critically ill Patients in a Tertiary Care Centre in Western Region of Nepal
}

\author{
Thapa $\mathrm{P},{ }^{1}$ Chakraborty PK, ${ }^{1}$ Khattri JB, ${ }^{1}$ Ramesh $\mathrm{K},{ }^{1}$ Sharma $\mathrm{P}^{2}$
}

${ }^{1}$ Department of Psychiatry

Manipal College of Medical Sciences

Phulbari-11, Pokhara, Nepal

${ }^{2}$ Mental Disease Treatment and Rehabilitation Centre

Attarkhel, Kathmandu

\section{Corresponding Author}

Prakash Thapa

Department of Psychiatry

Manipal College of Medical Sciences

Phulbari-11, Pokhara, Nepal

E-mail: prakashthapa324@gmail.com

\section{Citation}

Thapa P, Chakraborty PK, Khattri JB, Ramesh K, Sharma P. Delirium in Critically ill patients in a Tertiary Care Centre in Western Region of Nepal. Kathmandu Univ Med J 2014;46(2):117-20.

\section{ABSTRACT}

\section{Background}

Delirium affects a significant proportion of critically ill patients admitted in hospital. It is associated with various adverse outcomes. Despite its enormous prognostic significance it tends to be underdiagnosed. There is a dearth of studies on risk factors of delirium in our setting.

\section{Objectives}

The main objectives of this study was to find out the prevalence, rate of non recognition and risk factors associated with delirium in hospitalized critically ill patients.

\section{Methods}

A hospital based cross-sectional study was carried out. Data was collected using a predesigned semi-structured proforma and Intensive care delirium screening checklist was used to screen for delirium in patients admitted in various wards of Manipal teaching hospital, Pokhara, Nepal.

\section{Results}

Ninety five cases were included in the analysis. The mean age of study group was $58.9 \pm 19.1$ years. Delirium was present in 15/95 cases and it was not recognized by treating physician in about one third of cases. Odds ratio (OR) was statistically significantly increased in patients with history of stroke (OR=4.484 95\% $\mathrm{Cl}=1.0896 ; 18.459)$, alcohol use (OR=10.792 95\% Cl=2.906;40.072), smoking (OR= $4.83695 \% \mathrm{Cl}=1.411 ; 16.576)$, use of restraint (OR=17.143 95\% Cl=4.401;66.766), nasogastric tube placement $(\mathrm{OR}=7.73195 \% \mathrm{Cl}=2.348 ; 25.452)$ and use of Foley's catheter ( $\mathrm{OR}=12.00095 \% \mathrm{Cl}=3.072 ; 46.877)$.

\section{Conclusion}

About $16 \%$ of critically ill patients were found to be delirious. In about one third of the cases delirium was not recognized. Both patient related and iatrogenic factors may increase the risk of delirium in hospitalized critically ill patients.

\section{KEY WORDS}

Critical care, delirium, non-recognition 


\section{INTRODUCTION}

Delirium is defined as an etiologically nonspecific syndrome characterized by concurrent disturbance of consciousness and attention, perception, thinking, memory, psychomotor behavior, emotion, and the sleep-wake cycle. ${ }^{1}$ Many different terms have been used to describe this syndrome including Intensive Care Unit (ICU) psychosis, acute confusional state, acute brain failure and encephalopathy. ${ }^{2,3}$ Delirium has been reported to occur in $20-80 \%$ of patients in medical and surgical ICU setting. ${ }^{4-9}$ It is associated with various adverse outcomes including self extubation, removal of catheter, ${ }^{6}$ prolonged hospital stay, ${ }^{10}$ increased mortality, ${ }^{4,11,12}$ increased health care cost, ${ }^{13}$ and long term cognitive impairment. ${ }^{14,15}$ Despite high prevalence and enormous prognostic significance delirium often goes unrecognized. ${ }^{16}$

Risk factors for delirium can be divided into predisposing factors which may be non modifiable e.g. age, alcoholism, Apo E4 polymorphism and precipitating factors which include factors related to illness or iatrogenic factors which may be preventable e.g. hypotension, metabolic disturbance, restraints. ${ }^{17}$ Critically ill patients are typically exposed to multiple factors that precipitate delirium. ${ }^{10}$

Early recognition of delirium and institution of preventive measures improve the quality of critical care immensely. For this purpose, knowledge about prevalence of delirium, the chance of it being recognized, and the common risk factors is essential. Though these factors have been studied in the other countries, these data may not be generalizable in our context because of differences in practice settings. This study aims to find out the prevalence of delirium, chances of missing the diagnosis of delirium and risk factors that are present in our settings.

\section{METHOD}

A hospital based, cross sectional study was carried out after obtaining approval from institutional review board of Manipal College of medical sciences, Pokhara, Nepal. Data was collected from patients admitted in ICU, Neuro ICU, Postoperative ward, Semi ICU and COPD block of Manipal Teaching Hospital, Phulbari, Pokhara, Nepal. Patients younger than 15 years of age and those who were intubated or mechanically ventilated were excluded from the study. Informed consent was obtained from patients or their next of kin where appropriate. Those who failed to provide informed consent were excluded from the study.

Interns and residents working in respective departments were requested for data collection. Those who agreed were given a short introduction about the study and instructions about data collection were given by the first author. A predesigned semi-structured proforma was used to collect the base line demographic variables and the risk factors associated with delirium.
Intensive care delirium screening checklist (ICDSC) was used to identify delirium. ICDSC consists of eight items; each rated 1 (present) or 0 (absent). Each patient was given a score of $0-8$. A cut off point of 4 was used to identify delirium. At this cut off point, ICDSC has a sensitivity of $99 \%$ and specificity of $64 \%$ for identifying delirium. ${ }^{5}$

Data were entered in statistical software SPSS version 17.0. The odds of developing delirium when various risk factors were present was assessed by calculating odds risk (OR) with its $95 \%$ confidence interval $(\mathrm{Cl})$.

\section{RESULT}

Data was collected from a total of 100 patients. Five cases were excluded from analysis due to incomplete data hence the remaining 95 cases comprised of the study group. The mean age of the study group was $58.9 \pm 19.1$ years ( $\min =17$; $\max =85$ years). Among them 42 (44\%) were male and 53 (56\%) were female. The sociodemographic data of the study group is presented in table 1.

Table 1. Showing sociodemographic variables

\begin{tabular}{|c|c|c|}
\hline Variables & & N (\%) \\
\hline \multirow{2}{*}{ Domicile } & Rural & $34(35.8 \%)$ \\
\hline & Urban & $61(64.2 \%)$ \\
\hline \multirow{6}{*}{ Education } & Illeterate & $61(64.2 \%)$ \\
\hline & Literate & $6(6.3 \%)$ \\
\hline & Primary & $12(12.6 \%)$ \\
\hline & Secondary & $12(12.6 \%)$ \\
\hline & Higher Secondary & $2(2.1 \%)$ \\
\hline & Higher & $2(2.1 \%)$ \\
\hline \multirow{3}{*}{ Socioeconomic Status } & Lower & $24(25.3 \%)$ \\
\hline & Middle & 66 (69.5\%) \\
\hline & Upper & $5(5.3 \%)$ \\
\hline
\end{tabular}

Among these 95 patients delirium was suspected by treating physician in ten patients. When all of them were screened using ICDSC, 15 patients met criteria for delirium. So, delirium was not recognized in five out of 15 patients who had delirium; leading to a rate of nonrecognition of delirium of about $33 \%$.

In the current study statistically significant increase in odds ratio (OR) of delirium occurrence was seen in presence of six risk factors as seen in table 2 . These factors included predisposing factors like past history of stroke (OR=4.484 95\% Cl=1.0896; 18.459), alcohol use (OR=10.792 $95 \% \mathrm{Cl}=2.906 ; 40.072)$, smoking $(\mathrm{OR}=4.83695 \% \mathrm{Cl}=$ $1.411 ; 16.576)$. Other factors associated with statistically significant increase in odds of delirium occurrence were mainly treatment related factors i.e. use of restraint (OR=17.143 95\% Cl=4.401;66.766), nasogastric tube placement $(\mathrm{OR}=7.73195 \% \mathrm{Cl}=2.348 ; 25.452)$ and use of Foley's catheter (OR=12.000 95\% $\mathrm{Cl}=3.072 ; 46.877)$. 
Table 2. Odds ratio of various factors causing delirium

\begin{tabular}{|lcl|}
\hline Variables & Odds ratio & $\begin{array}{l}95 \% \text { confidence } \\
\text { interval }\end{array}$ \\
\hline Visual impairment & 0.24 & $0.03-2.00$ \\
\hline Hearing impairment & 0.44 & $0.05-3.75$ \\
\hline Past history of stroke & 4.48 & $1.08-18.45^{*}$ \\
\hline History of alcohol use & 10.79 & $2.90-40.07^{*}$ \\
\hline History of smoking & 4.83 & $1.41-16.57^{*}$ \\
\hline NG tube & 7.73 & $2.34-25.45^{*}$ \\
\hline Foleys tube & 12.00 & $3.07-46.87^{*}$ \\
\hline Use of restraint & 17.14 & $4.40-66.76^{*}$ \\
\hline Being treated with opiates & 0.78 & $0.15-3.88$ \\
\hline $\begin{array}{l}\text { Being treated with benzodi- } \\
\text { azepines }\end{array}$ & 3.04 & $0.66-13.83$ \\
\hline $\begin{array}{l}\text { History of any surgical proce- } \\
\text { dure in current admission }\end{array}$ & 1.60 & $0.48-5.28$ \\
\hline
\end{tabular}

Current study failed to find significant increase in odds of delirium occurrence in presence of risk factors like presence of visual (OR=0.246 95\% Cl=0.030;2.000) or hearing impairment $(\mathrm{OR}=0.44895 \% \mathrm{Cl}=0.053 ; 3.756)$, being treated with benzodiazepine $(\mathrm{OR}=3.04295 \% \mathrm{Cl}=0.669 ; 13.830)$ or opiates (OR=0.781 95\% Cl=0.1572;3.880) during current admission and history of any surgical procedure during current admission ( $\mathrm{OR}=1.60595 \% \mathrm{Cl}=0.488 ; 5.281$ ) as seen in table 2.

\section{DISCUSSION}

Current study was carried out to find out the prevalence of delirium in critically ill patients in our setting. It also aimed to find out the rate of nonrecognition of delirium by treating physicians. In the present study, among 95 patients screened for delirium using ICDSC 15 patients met criteria for delirium. Hence the prevalence of delirium in hospitalized critically ill patients was around 16\% (15/95); however it was recognized by treating physician in ten patients only. The rate of nonrecognition of delirium in current study was around 33\% (five out of 15 patients). This rate is comparable to previously reported rate of nonrecognition of $36.4 \%{ }^{18}$

Previous studies have proposed various factors to contribute to nonrecognition of delirium. It includes factors such as; not giving a high diagnostic and therapeutic priority to delirium, ${ }^{18}$ failure to recognize hypoactive variety of delirium and overreliance on orientation when diagnosing delirium. ${ }^{19,20}$ Nonrecognition is problematic as mortality seems to increase by about $11 \%$ for every additional

\section{REFERENCES}

1. World Health Organization. The ICD-10 classification of mental and behavioural disorders: Clinical description and diagnostic guidelines. Geneva,1992.

2. Mc Guirre BE, Besten CJ, Ryan CJ, Gallagher J. Intensive Care Unit Syndrome: a dangerous misnomer. Arch intern Med 2000;160:906-9.
48 hours of active delirium, ${ }^{21}$ as well as leading to other complications like prolonged hospital stay, ${ }^{10}$ increased health care cost, ${ }^{13}$ and long term cognitive impairment. ${ }^{14,15}$ Routine use of screening instruments like ICDSC could help prevent these complications by aiding in early diagnosis.

Current study found statistically significant increase in odds of delirium occurence in those patients who had past history of stroke, history of alcohol use, smoking. Previous studies have also found history of stroke, ${ }^{22}$ alcohol use and smoking to be risk factors for delirium. ${ }^{23}$ It is therefore necessary to screen for the presence of these factors at the time of admission of critically ill patients.

The odds of delirium occurence was found to be statistically significantly higher among those patients who were restrained or those who had nasogastric tube or Foley's catheter inserted. All of these factors have been previously shown to increase the risk of delirium. ${ }^{23}$ Due to cross-sectional nature of current study we couldn't asses the direction of association between these factors. It is possible that some of these measures might have been instituted once delirium had started.

There are conflicting evidence regarding risk of delirium with use of opiates and benzodiazepines. ${ }^{6,12,24,25}$ Current study did not find a statistically significant increase in risk of occurrence of delirium with use of benzodiazepine (OR= $3.04295 \% \mathrm{Cl}=0.669 ; 13.830$ ) or use of opiates (OR=0.781 $95 \% \mathrm{Cl}=0.1572 ; 3.880)$ during current admission. This finding should be interpreted with limitation of current study in mind; which is its relatively small size. With a larger sample statistical significance might have been reached other risk factors as well. Hence indiscriminate use of opiates or benzodiazepines in critically ill patients cannot be recommended by current study alone.

As mentioned before the major limitations of this study includes a relatively small sample size and its crosssectional nature. Future studies in this area should address these limitations.

\section{CONCLUSIONS}

About $16 \%$ of patients were found to be having delirium. Delirium was not recognized by treating physician in about a third of cases. Routine use of screening tool like ICDSC in critical care setting may aid in recognition of delirium. The risk of delirium was more in patients with history of stroke, alcohol use and smoking. Similarly use of restraint, Foley's tube and nasogastric tube was associated with increased risk of delirium.

3. Justic M. Does 'ICU Psychosis' Really exist? Crit Care Nurse 2000;20: 28-37.

4. Ely EW, Shintani A, Truman B, Speroff T, Gordon SM, Hawel FE et al. Delirium as a predictor of mortality in mechanically ventillated patients in Intensive Care unit. JAMA 2004;291:1753-1762. 
5. Bergeron M, Dubvis MJ, Dumount M, Dial S, Skrobik Y. Intensive Care Delirium Screening Check list: evaluation of a new screening tool. Intensive Care Med. 2001;27:859-864.

6. Dubois MJ, Bergeron M, Dumont M, Dial S, Shorbik Y. Delirium in Intensive care unit. A study of risk factors. Intensive Care Med 2001; 27:1297-1304.

7. McNicoll L, Pisani MA, Zhong Y, Ely EW, Siegel MD, Inonye SH. Delirium in the intensive care unit: occurrence and clinical course in older patients. J Am Geriatr Soc 2003;51:591-8.

8. Pandheripande $\mathrm{P}$, Cotton BA, Shintani A, Thomson J, Pun BT, Morris $\mathrm{JA}$, et al. Prevalence and risk factors for development of delirium in Surgical and Trauma ICU patients. J Trauma 2008;65(1):34-41.

9. Thomason JW, Shinteni A, Peterson JF, Pun BT, Jacuson JC, Ely EW. Intensive care unit delirium is an independent Predictor of longer hospital stay. A prospective analysis of 861 non ventillated patients. Crit Care 2005;9:R375-R381.

10. Ely EW, Gautam S, Margolin R, Francis J, May J, Speroff J, et al. The impact of delirium in the intensive care unit on hospital length of stay. Intensive Care Med 2001;27:1892-1900.

11. Lin SM, Liu CP, Wang $C H$, Lin $C H$, Hueng CD, Hueng PY, et al. The impact of delirium on the Survival of mechanically ventillated Patients. Crit Care Med 2004;32(11):2254-2259.

12. Ouimet S, Kavenagh BP, Gotlfried SB, Skrobik Y. Incidence, risk factors and consequence of ICU delirium in mechanically ventillated patients. Crit Care Med 2004;32:955-962.

13. Leslie DL, Marcantonio ER, Zhang Y, Leo-Summers L, Inouye SK. One year health costs associated with delirium in elderly population. Arch Intern Med 2008;168(1):27-32.

14. Jackson JC, Gordon SM, Hert RP, Hopkin RO, Ely EW. The association between delirium and cognitive decline. A review of empirical literature. Neuropsychol Rev 2004;14:87-98.

15. Jackson JC, Gorson SM, Girard TD, Thomesson JWW, Pun BJ, Dunn $J$, et al. Delirium as a risk factor for long term cognitive impairment in mechanically ventillated ICU survivors. Am J Respir Crit Care Med 2007;175:A22.
16. Ely EW, Stephens RK, Jackson JC, Thomasson JW, Truman B, Gordon $S$, et al. Current opinion regarding the importance, diagnosis, and management of delirium in the intensive care unit: a survey of 912 health care professionals. Crit Care Med 2004;32:106-112.

17. Inouye SK, Charpentier PA. Precipitating factors for delirium in hospitalized elderly persons. Predictive model \& interrelationship with baseline vulnerability. JAMA 1996;275:852-857.

18. Ryan DJ, O'Regan NA, Caoimh RO, Clare J, O'Conner M, Leonard M, et al. Delirium in adult acute hospital population: Predictors, Prevalence and detection. 2013;3:e001772. doi:10.1136/bmjopen-2012-001772

19. Inouye SK, Foreman MD, Mion LC, Katz KH, Cooney LM. Nurses' recognition of delirium and its symptoms: comparison of nurse and researcher ratings. Arch Intern Med 2001;161:2467-73.

20. Souder E, O'Sullivan PS. Nursing documentation versus standardized assessment of cognitive status in hospitalized medical patients. App Nurs Res 2000;13:29-36.

21. Gonzalez M, Martinez G, Calderon J, Villarroel L, Yuri F, Rojas C, et al. Impact of delirium on short-term mortality in elderly inpatients: a prospective cohort study. Psychosomatics 2009;50:234-8.

22. Kostera S, Hensens AG, Schuurmans MJ, Palen JVD. Risk factors of delirium after cardiac surgery: a systematic review. Eur J Cardiovasc Nurs 2011;10(4): 197-204.

23. Rompaey BV, Elseviers MM, Schuurmans MJ, Shortridge-Bagget LM, Truijen S, Bossaert L. Risk factors for delirium in intensive care patients: a prospective cohort study. Crit care 2009;13(3): R77 (doi:10.1186/cc7892)

24. Gaudreau JD, Gagnon P, Roy MA, Harel F, Trembley A. Opioid medication and longitudinal risk of delirium in hospitalized cancer patient. Cancer 2007;109(11):2365-73.

25. Clegg A, Young JB. Which medication to avoid in people at risk of delirium: a systematic review. Age ageing 2011;40(1):23-29. 